\title{
Fixed points of generalized Meir-Keeler contraction mappings in $b$-metric-like spaces
}

Nayereh Gholamian and Mahnaz Khanehgir*

${ }^{\text {*Correspondence: }}$

khanehgir@mshdiau.ac.ir

Department of Mathematics,

Mashhad Branch, Islamic Azad

University, Mashhad, Iran

\begin{abstract}
In this paper, we introduce the notion of generalized Meir-Keeler contraction mappings in the setup of $b$-metric-like spaces. Then we establish some fixed point results for this class of contractions. We also provide some examples to verify the effectiveness and applicability of our main results.
\end{abstract}

MSC: Primary $47 \mathrm{H} 10$; secondary $54 \mathrm{H} 25$

Keywords: $\alpha$-admissible; fixed point; Meir-Keeler contraction; $b$-metric-like

\section{Introduction and preliminaries}

In 1969, Meir and Keeler [1] proved the following very attractive fixed point theorem, which is a generalization of the Banach contraction principle [2].

Definition 1.1 [1] Let $(X, d)$ be a metric space. Then a mapping $T$ on $X$ is said to be a Meir-Keeler contraction (MKC, for short) if for any $\varepsilon>0$, there exists $\delta>0$ such that

$$
\varepsilon \leq d(x, y)<\varepsilon+\delta(\varepsilon) \Rightarrow d(T x, T y)<\varepsilon
$$

for all $x, y \in X$.

Theorem 1.2 [1] Let $(X, d)$ be a complete metric space. If $T: X \rightarrow X$ is a Meir-Keeler contraction, then $T$ has a unique fixed point.

Alsulami et al. [3] defined two types of generalized $\alpha$-admissible [4] Meir-Keeler contractions and proved some fixed point theorems for these kinds of mappings. Meir-Keeler contraction has many generalizations in the area studied by some scholars (cf. e.g. [5-8]).

On the other hand, Amini-Harandi [9] presented a new extension of the concept of the partial metric space [10], called a metric-like space. The concept of $b$-metric-like space which generalizes the notions of partial metric space, metric-like space and $b$-metric space [11] was introduced by Alghamdi et al. in [12]. They established some fixed point theorems in partial metric spaces, $b$-metric spaces and $b$-metric-like spaces. It is well known that all these spaces are generalization of the usual metric spaces. There are several types of generalized metric spaces [13, 14], introduced by modifying and improving metric axioms. These generalized metric spaces often appear to be metrizable and the contraction conditions may be preserved under special transforms. Hence the fixed point theory in such

(C) 2016 Gholamian and Khanehgir. This article is distributed under the terms of the Creative Commons Attribution 4.0 International License (http://creativecommons.org/licenses/by/4.0/), which permits unrestricted use, distribution, and reproduction in any medium, provided you give appropriate credit to the original author(s) and the source, provide a link to the Creative Commons license, and indicate if changes were made. 
spaces may be a consequence of the fixed point theory in certain metric spaces. However, it is not true that all generalized fixed point results become evident in this way. More precisely, these results are based on some contractive conditions, and some of these conditions do not remain authentic when one considers the problem in the associated metric space [15].

In the present work, using the concepts of Meir-Keeler contractions and $b$-metric-like spaces, we define a new concept of generalized Meir-Keeler contraction on a $b$-metric-like space. Then we investigate some fixed point results for this class of contractions. We give an example that shows that our results in $b$-metric-like spaces may not be deduced from certain ones in $b$-metric spaces. We also provide some examples to support the usability of our results.

It is convenient and, more importantly helpful to recall some basic definitions and facts which will be used further on. Throughout this paper, we denote by $\mathbb{R}^{+}$the set of nonnegative real numbers.

Definition 1.3 [11] Let $X$ be a nonempty set, and let the function $d: X \times X \rightarrow \mathbb{R}^{+}$satisfies:

(b1) $d(x, y)=0$ if and only if $x=y$,

(b2) $d(x, y)=d(y, x)$ for all $x, y \in X$,

(b3) there exists a real number $s \geq 1$ such that $d(x, z) \leq s[d(x, y)+d(y, z)]$ for all $x, y, z \in X$.

Then $d$ is called a $b$-metric on $X$. In this case the pair $(X, d)$ is called a $b$-metric space with coefficient $s$.

Definition 1.4 [16] A partial $b$-metric on a nonempty set $X$ is a mapping $p_{b}: X \times X \rightarrow \mathbb{R}^{+}$ such that for some real number $s \geq 1$ and all $x, y, z \in X$ :

$\left(\mathrm{p}_{b} 1\right) x=y$ if and only if $p_{b}(x, x)=p_{b}(x, y)=p_{b}(y, y)$,

$\left(\mathrm{p}_{b} 2\right) p_{b}(x, x) \leq p_{b}(x, y)$,

$\left(\mathrm{p}_{b} 3\right) p_{b}(x, y)=p_{b}(y, x)$,

$\left(\mathrm{p}_{b} 4\right) p_{b}(x, y) \leq s\left[p_{b}(x, z)+p_{b}(z, y)\right]-p_{b}(z, z)$.

A pair $\left(X, p_{b}\right)$ is called a partial $b$-metric space, if $X$ is a nonempty set and $p_{b}$ is a partial $b$-metric on $X$. The number $s$ is called the coefficient of $\left(X, p_{b}\right)$.

It is clear that if in Definitions 1.3 and $1.4 s=1$, then they are the usual metric and partial metric space, respectively.

Definition 1.5 [9] A metric-like on a nonempty set $X$ is a mapping $\sigma: X \times X \rightarrow \mathbb{R}^{+}$such that for all $x, y, z \in X$ :

( $\sigma 1) \sigma(x, y)=0$ implies $x=y$,

$(\sigma 2) \sigma(x, y)=\sigma(y, x)$,

( $\sigma 3) \sigma(x, y) \leq \sigma(x, z)+\sigma(z, y)$.

The pair $(X, \sigma)$ is called a metric-like space.

Example 1.6 [17] Let $X=[0,1]$. Then the mapping $\sigma_{1}: X \times X \rightarrow \mathbb{R}^{+}$defined by $\sigma_{1}(x, y)=$ $x+y-x y$ is a metric-like on $X$. 
Example 1.7 [17] Let $X=\mathbb{R}$, then the mappings $\sigma_{i}: X \times X \rightarrow \mathbb{R}^{+}(i \in\{2,3,4\})$ defined by

$$
\begin{aligned}
& \sigma_{2}(x, y)=|x|+|y|+a, \\
& \sigma_{3}(x, y)=|x-b|+|y-b|, \\
& \sigma_{4}(x, y)=x^{2}+y^{2},
\end{aligned}
$$

are metrics-like on $X$, where $a \geq 0$ and $b \in \mathbb{R}$.

Definition 1.8 [12] Let $X$ be a nonempty set and $s \geq 1$ be a given real number. A function $\sigma_{b}: X \times X \rightarrow \mathbb{R}^{+}$is a $b$-metric-like if, for all $x, y, z \in X$, the following conditions are satisfied:

$\left(\sigma_{b} 1\right) \quad \sigma_{b}(x, y)=0$ implies $x=y$,

$\left(\sigma_{b} 2\right) \sigma_{b}(x, y)=\sigma_{b}(y, x)$,

$\left(\sigma_{b} 3\right) \sigma_{b}(x, y) \leq s\left[\sigma_{b}(x, z)+\sigma_{b}(z, y)\right]$.

A $b$-metric-like space is a pair $\left(X, \sigma_{b}\right)$ such that $X$ is a nonempty set and $\sigma_{b}$ is a $b$-metriclike on $X$. The number $s$ is called the coefficient of $\left(X, \sigma_{b}\right)$.

Some examples of $b$-metric-like spaces can be constructed with the help of the following proposition.

Proposition 1.9 [18] Let $(X, \sigma)$ be a metric-like space and $\sigma_{b}(x, y)=[\sigma(x, y)]^{p}$, where $p>1$. Then $\sigma_{b}$ is a b-metric-like with coefficient $s=2^{p-1}$.

Every partial $b$-metric space is a $b$-metric-like space with the same coefficient $s$ and every $b$-metric space is also a $b$-metric-like space with the same coefficient $s$. However, the converses of these facts need not hold. For instance, assume that $p>1$, then $\sigma_{1}^{p}$ and $\sigma_{4}^{p}$ are $b$-metrics-like, but $\sigma_{1}^{p}$ is not $b$-metric and $\sigma_{4}^{p}$ is not partial $b$-metric.

Each $b$-metric-like $\sigma_{b}$ on a nonempty set $X$ generates a topology $\tau_{\sigma_{b}}$ on $X$ whose base is the family of open $\sigma_{b}$-balls $\left\{B_{\sigma_{b}}(x, \varepsilon): x \in X, \varepsilon>0\right\}$ where $B_{\sigma_{b}}(x, \varepsilon)=\left\{y \in X: \mid \sigma_{b}(x, y)-\right.$ $\left.\sigma_{b}(x, x) \mid<\varepsilon\right\}$ for all $x \in X$ and $\varepsilon>0$.

Now, we recall the concepts of Cauchy sequence and convergent sequence in the framework of $b$-metric-like spaces.

Definition 1.10 [12] Let $\left(X, \sigma_{b}\right)$ be a $b$-metric-like space with coefficient $s,\left\{x_{n}\right\}$ be any sequence in $X$ and $x \in X$. Then:

(i) The sequence $\left\{x_{n}\right\}$ is said to be convergent to $x$ with respect to $\tau_{\sigma_{b}}$ if $\lim _{n \rightarrow \infty} \sigma_{b}\left(x_{n}, x\right)=\sigma_{b}(x, x)$.

(ii) The sequence $\left\{x_{n}\right\}$ is said to be a Cauchy sequence in $\left(X, \sigma_{b}\right)$, if $\lim _{n, m \rightarrow \infty} \sigma_{b}\left(x_{n}, x_{m}\right)$ exists and is finite.

(iii) $\left(X, \sigma_{b}\right)$ is said to be a complete $b$-metric-like space if for every Cauchy sequence $\left\{x_{n}\right\}$ in $X$ there exists $x \in X$ such that

$$
\lim _{n, m \rightarrow \infty} \sigma_{b}\left(x_{n}, x_{m}\right)=\lim _{n \rightarrow \infty} \sigma_{b}\left(x_{n}, x\right)=\sigma_{b}(x, x) .
$$

Note that in a $b$-metric-like space the limit of a convergent sequence may not be unique (since already partial metric spaces share this property). 
Definition 1.11 [19] Suppose that $\left(X, \sigma_{b}\right)$ is a $b$-metric-like space. A mapping $T: X \rightarrow X$ is said to be continuous at a point $x \in X$, if for every $\varepsilon>0$ there exists a $\delta>0$ such that $T\left(B_{\sigma_{b}}(x, \delta)\right) \subseteq B_{\sigma_{b}}(T x, \varepsilon)$. The mapping $T$ is continuous on $X$ if it is continuous at each point $x$ in $X$.

Note that if $T: X \rightarrow X$ is a continuous mapping and $\left\{x_{n}\right\}$ is a sequence in $X$ with $\lim _{n \rightarrow \infty} \sigma_{b}\left(x_{n}, x\right)=\sigma_{b}(x, x)$, then $\lim _{n \rightarrow \infty} \sigma_{b}\left(T x_{n}, T x\right)=\sigma_{b}(T x, T x)$.

Samet et al. in [4] introduced the concept of $\alpha$-admissible mappings and established some new fixed point theorems for these mappings. Thereafter, many researchers improved and generalized fixed point results by using this notion for single valued and multivalued mappings (cf. e.g. $[3,7,20]$ for details).

Definition 1.12 [3] Let $X$ be a nonempty set, $T: X \rightarrow X$ be a mapping and $\alpha: X \times X \rightarrow$ $[0, \infty)$ be a function. Then $f$ is said to be $\alpha$-admissible if for all $x, y \in X$ we have

$$
\alpha(x, y) \geq 1 \quad \Rightarrow \quad \alpha(T x, T y) \geq 1 .
$$

Definition 1.13 [3] A mapping $T: X \rightarrow X$ is called triangular $\alpha$-admissible if it is $\alpha$-admissible and, moreover, it satisfies the following implication:

$$
\alpha(x, y) \geq 1, \quad \alpha(y, z) \geq 1 \quad \Rightarrow \quad \alpha(x, z) \geq 1,
$$

where $x, y, z \in X$.

The following lemma is useful in proving our main results, stated and proved according to [7], Lemma 7.

Lemma 1.14 Let $\left(X, \sigma_{b}\right)$ be a b-metric-like space and $T: X \rightarrow X$ be a triangular $\alpha$-admissible mapping. Assume that there exists $x_{0} \in X$ such that $\alpha\left(x_{0}, T x_{0}\right) \geq 1$ and $\alpha\left(T x_{0}, x_{0}\right) \geq 1$. If $x_{n}=T^{n} x_{0}$, then $\alpha\left(x_{m}, x_{n}\right) \geq 1$ for all $m, n \in \mathbb{N}$.

\section{Main results}

In this section, first we describe the concept of generalized Meir-Keeler contraction on a $b$-metric-like space which can be regarded as an extension of the Meir-Keeler contractions defined in [1]. Then we demonstrate some fixed point results for this class of contractions.

Definition 2.1 Suppose that $\left(X, \sigma_{b}\right)$ is a $b$-metric-like space with coefficient $s$. A triangular $\alpha$-admissible mapping $T: X \rightarrow X$ is said to be generalized Meir-Keeler contraction if for every $\varepsilon>0$ there exists $\delta>0$ such that

$$
\varepsilon \leq \beta\left(\sigma_{b}(x, y)\right) \sigma_{b}(x, y)<\varepsilon+\delta \quad \text { implies } \quad \alpha(x, y) \sigma_{b}(T x, T y)<\varepsilon,
$$

for all $x, y \in X$ where $\beta:[0, \infty) \rightarrow\left(0, \frac{1}{s}\right)$ is a given function.

Remark 2.2 Let $T$ be a generalized Meir-Keeler contractive mapping. Then it is intuitively clear that

$$
\alpha(x, y) \sigma_{b}(T x, T y)<\beta\left(\sigma_{b}(x, y)\right) \sigma_{b}(x, y),
$$

for all $x, y \in X$ when $x \neq y$. 
We are now in a position to define two types of generalized Meir-Keeler contractions on $b$-metric-like spaces, say type (I) and type (II).

Definition 2.3 Let $\left(X, \sigma_{b}\right)$ be a $b$-metric-like space with coefficient $s$. A triangular $\alpha$-admissible mapping $T: X \rightarrow X$ is said to be generalized Meir-Keeler contraction of type (I) if for every $\varepsilon>0$ there exists $\delta>0$ such that

$$
\varepsilon \leq \beta\left(\sigma_{b}(x, y)\right) M(x, y)<\varepsilon+\delta \quad \text { implies } \quad \alpha(x, y) \sigma_{b}(T x, T y)<\varepsilon,
$$

where

$$
M(x, y)=\max \left\{\sigma_{b}(x, y), \sigma_{b}(T x, x), \sigma_{b}(T y, y)\right\}
$$

for all $x, y \in X$.

Definition 2.4 Let $\left(X, \sigma_{b}\right)$ be a $b$-metric-like space with coefficient $s$. A triangular $\alpha$-admissible mapping $T: X \rightarrow X$ is said to be generalized Meir-Keeler contraction of type (II) if for every $\varepsilon>0$ there exists $\delta>0$ such that

$$
\varepsilon \leq \beta\left(\sigma_{b}(x, y)\right) N(x, y)<\varepsilon+\delta \quad \text { implies } \quad \alpha(x, y) \sigma_{b}(T x, T y)<\varepsilon,
$$

where

$$
N(x, y)=\max \left\{\sigma_{b}(x, y), \frac{1}{2}\left[\sigma_{b}(T x, x)+\sigma_{b}(T y, y)\right]\right\},
$$

for all $x, y \in X$.

In the following, we illustrate two important properties concerned with these new generalized Meir-Keeler contractions, which we will require in our subsequent arguments.

Remark 2.5 Suppose that $T: X \rightarrow X$ is a generalized Meir-Keeler contraction of type (I) (respectively, type (II)). Then

$$
\alpha(x, y) \sigma_{b}(T x, T y)<\beta\left(\sigma_{b}(x, y)\right) M(x, y) \quad\left(\text { respectively, } \beta\left(\sigma_{b}(x, y)\right) N(x, y)\right) \text {, }
$$

for all $x, y \in X$ when $M(x, y)>0$ (respectively, $N(x, y)>0$ ).

Remark 2.6 It is readily verified that $N(x, y) \leq M(x, y)$ for all $x, y \in X$, where $M(x, y)$ and $N(x, y)$ are defined in (3) and (5), respectively.

Next, we establish a fixed point theorem for generalized Meir-Keeler type contractions via a rational expression. The presented theorem is a generalization of the result of Samet et al. [8].

Theorem 2.7 Let $\left(X, \sigma_{b}\right)$ be a complete $b$-metric-like space and $T: X \rightarrow X$ be a triangular $\alpha$-admissible mapping. Suppose that the following conditions hold:

(a) there exists $x_{0} \in X$ such that $\alpha\left(x_{0}, T x_{0}\right) \geq 1, \alpha\left(T x_{0}, x_{0}\right) \geq 1$, 
(b) if $\left\{x_{n}\right\}$ is a sequence in $X$ such that $x_{n} \rightarrow z$ as $n \rightarrow \infty$ and $\alpha\left(x_{n}, x_{m}\right) \geq 1$ for all $n, m \in \mathbb{N}$, then $\alpha\left(x_{n}, z\right) \geq 1$ for all $n \in \mathbb{N}$,

(c) for each $\varepsilon>0$, there exists $\delta>0$ satisfying the following condition:

$$
\begin{aligned}
& 2 s \varepsilon \leq \sigma_{b}(y, T y) \frac{1+\sigma_{b}(x, T x)}{1+M(x, y)}+N(x, y)<s(2 \varepsilon+\delta) \quad \text { implies } \\
& \alpha(x, y) \sigma_{b}(T x, T y)<\varepsilon .
\end{aligned}
$$

Then $T$ has a fixed point in $X$.

Proof It is easy to observe that condition (6) implies that $x \neq y$ or $y \neq T y$ and also

$$
\alpha(x, y) \sigma_{b}(T x, T y)<\frac{1}{2 s} \sigma_{b}(y, T y) \frac{1+\sigma_{b}(x, T x)}{1+M(x, y)}+\frac{1}{2 s} N(x, y) .
$$

Let $x_{0} \in X$ be such that condition (a) holds and define a sequence $\left\{x_{n}\right\}$ in $X$ such that $x_{1}=$ $T x_{0}, x_{n+1}=T x_{n}$ for all $n \in \mathbb{N}$. We may suppose that $x_{n+1} \neq x_{n}$ for all $n \in \mathbb{N} \cup\{0\}$, otherwise $T$ has obviously a fixed point. Now, since $T$ is $\alpha$-admissible, then

$$
\alpha\left(x_{0}, x_{1}\right)=\alpha\left(x_{0}, T x_{0}\right) \geq 1 \quad \Rightarrow \quad \alpha\left(T x_{0}, T x_{1}\right)=\alpha\left(x_{1}, x_{2}\right) \geq 1,
$$

and repeatedly using (8) we obtain

$$
\alpha\left(x_{n}, x_{n+1}\right) \geq 1, \quad \forall n \in \mathbb{N} .
$$

Replace $x$ by $x_{n}$ and $y$ by $x_{n+1}$ in (7) and taking into account equation (9), we deduce

$$
\begin{aligned}
\sigma_{b}\left(x_{n+1}, x_{n+2}\right)= & \sigma_{b}\left(T x_{n}, T x_{n+1}\right) \\
\leq & \alpha\left(x_{n}, x_{n+1}\right) \sigma_{b}\left(T x_{n}, T x_{n+1}\right) \\
< & \frac{1}{2 s} \sigma_{b}\left(x_{n+1}, x_{n+2}\right) \frac{1+\sigma_{b}\left(x_{n}, x_{n+1}\right)}{1+M\left(x_{n}, x_{n+1}\right)} \\
& +\frac{1}{2 s} N\left(x_{n}, x_{n+1}\right),
\end{aligned}
$$

where

$$
M\left(x_{n}, x_{n+1}\right)=\max \left\{\sigma_{b}\left(x_{n}, x_{n+1}\right), \sigma_{b}\left(x_{n+1}, x_{n+2}\right)\right\} .
$$

We distinguish two following cases:

Case 1. Assume that $M\left(x_{n}, x_{n+1}\right)=\sigma_{b}\left(x_{n+2}, x_{n+1}\right)$. By virtue of Remark 2.6 and also (7) we observe that

$$
\begin{aligned}
\sigma_{b}\left(x_{n+1}, x_{n+2}\right) & =\sigma_{b}\left(T x_{n}, T x_{n+1}\right) \\
& \leq \alpha\left(x_{n}, x_{n+1}\right) \sigma_{b}\left(T x_{n}, T x_{n+1}\right) \\
& <\frac{1}{2 s} \sigma_{b}\left(x_{n+1}, x_{n+2}\right) \frac{1+\sigma_{b}\left(x_{n}, x_{n+1}\right)}{1+\sigma_{b}\left(x_{n+1}, x_{n+2}\right)}
\end{aligned}
$$




$$
\begin{aligned}
& +\frac{1}{2 s} \sigma_{b}\left(x_{n+1}, x_{n+2}\right) \\
\leq & \sigma_{b}\left(x_{n+1}, x_{n+2}\right),
\end{aligned}
$$

which gives a contradiction.

Case 2. Assume that $M\left(x_{n}, x_{n+1}\right)=\sigma_{b}\left(x_{n}, x_{n+1}\right)$. Then $N\left(x_{n}, x_{n+1}\right)=\sigma_{b}\left(x_{n}, x_{n+1}\right)$, too. Applying Remark 2.6, we get

$$
\begin{aligned}
\sigma_{b}\left(x_{n+1}, x_{n+2}\right) & <\frac{1}{2 s} \sigma_{b}\left(x_{n+1}, x_{n+2}\right) \frac{1+\sigma_{b}\left(x_{n}, x_{n+1}\right)}{1+\sigma_{b}\left(x_{n}, x_{n+1}\right)}+\frac{1}{2 s} \sigma_{b}\left(x_{n}, x_{n+1}\right) \\
& \leq \frac{1}{s} \sigma_{b}\left(x_{n}, x_{n+1}\right)
\end{aligned}
$$

Therefore

$$
\sigma_{b}\left(x_{n+1}, x_{n+2}\right)<\sigma_{b}\left(x_{n}, x_{n+1}\right)
$$

for all $n$. That is, $\left\{\sigma_{b}\left(x_{n}, x_{n+1}\right)\right\}$ is a strictly decreasing positive sequence in $\mathbb{R}^{+}$and it converges to some $r \geq 0$. We claim that $r=0$. To support the claim, let it be untrue. Then we have $r>0$. We assert that

$$
0<r \leq \sigma_{b}\left(x_{n}, x_{n+1}\right), \quad \text { for all } n \in \mathbb{N} \text {. }
$$

Since the condition (6) holds for every $\varepsilon>0$, we may choose $\varepsilon=\frac{r}{s}$ and let $\delta$ be such that satisfying condition (6). We know that $\lim _{n \rightarrow \infty}\left[\sigma_{b}\left(x_{n+1}, x_{n+2}\right)+\sigma_{b}\left(x_{n}, x_{n+1}\right)\right]=2 r$. Hence there exists $N_{0} \in \mathbb{N}$ such that $2 r<\sigma_{b}\left(x_{N_{0}+1}, x_{N_{0}+2}\right)+\sigma_{b}\left(x_{N_{0}}, x_{N_{0}+1}\right)<2 r+\delta$. Consequently,

$$
\begin{aligned}
2 s \varepsilon & <\sigma_{b}\left(x_{N_{0}+1}, x_{N_{0}+2}\right)+\sigma_{b}\left(x_{N_{0}}, x_{N_{0}+1}\right) \\
& =\sigma_{b}\left(x_{N_{0}+1}, T x_{N_{0}+1}\right) \frac{1+\sigma_{b}\left(x_{N_{0}}, T x_{N_{0}}\right)}{1+M\left(x_{N_{0}}, x_{N_{0}+1}\right)}+N\left(x_{N_{0}}, x_{N_{0}+1}\right) \\
& <2 s \varepsilon+\delta \\
& \leq s(2 \varepsilon+\delta),
\end{aligned}
$$

and using (6) and (9)

$$
\sigma_{b}\left(x_{N_{0}+1}, x_{N_{0}+2}\right) \leq \alpha\left(x_{N_{0}}, x_{N_{0}+1}\right) \sigma_{b}\left(T x_{N_{0}}, T x_{N_{0}+1}\right)<\frac{r}{s} \leq r
$$

which leads to a contradiction with the condition (10). Thus, $r=0$, that is,

$$
\lim _{n \rightarrow \infty} \sigma_{b}\left(x_{n}, x_{n+1}\right)=0
$$

We claim that the sequence $\left\{x_{n}\right\}$ is a Cauchy sequence. Let $\varepsilon>0$. Let $\delta^{\prime}=\min \{\delta, \varepsilon, 1\}$. From (11) there exists $k \in \mathbb{N}$ such that

$$
\sigma_{b}\left(x_{m}, x_{m+1}\right)<\frac{\delta^{\prime}}{4}, \quad \forall m \geq k .
$$


Now, we define the set $\Lambda \subset X$ by

$$
\Lambda:=\left\{x_{p} \mid p \geq k, \sigma_{b}\left(x_{p}, x_{k}\right)<s\left(2 \varepsilon+\frac{\delta^{\prime}}{2}\right)\right\}
$$

We will show that $T(\Lambda) \subset \Lambda$. Let $\lambda \in \Lambda$. There exists $p \geq k$ such that $\lambda=x_{p}$ and $\sigma_{b}\left(x_{p}, x_{k}\right)<$ $s\left(2 \varepsilon+\frac{\delta^{\prime}}{2}\right)$.

If $p=k$, then $T(\lambda)=x_{k+1} \in \Lambda$ by (12). We will assume that $p>k$. First, we suppose that $2 s \varepsilon \leq \sigma_{b}\left(x_{p}, x_{k}\right)$, so

$$
2 s \varepsilon \leq \sigma_{b}\left(x_{p}, x_{k}\right)<s\left(2 \varepsilon+\frac{\delta^{\prime}}{2}\right)
$$

Let us prove that

$$
\varepsilon \leq \frac{1}{2 s} \sigma_{b}\left(x_{k}, x_{k+1}\right) \frac{1+\sigma_{b}\left(x_{p}, x_{p+1}\right)}{1+M\left(x_{p}, x_{k}\right)}+\frac{1}{2 s} N\left(x_{p}, x_{k}\right)<\varepsilon+\frac{\delta^{\prime}}{2} .
$$

We know $\sigma_{b}\left(x_{p}, x_{k}\right) \leq N\left(x_{p}, x_{k}\right)$, then from (13) we get

$$
\varepsilon \leq \frac{1}{2 s} \sigma_{b}\left(x_{p}, x_{k}\right) \leq \frac{1}{2 s} \sigma_{b}\left(x_{k}, x_{k+1}\right) \frac{1+\sigma_{b}\left(x_{p}, x_{p+1}\right)}{1+M\left(x_{p}, x_{k}\right)}+\frac{1}{2 s} N\left(x_{p}, x_{k}\right) .
$$

Regarding (12) and since $2 s \varepsilon \leq \sigma_{b}\left(x_{p}, x_{k}\right)$, then $M\left(x_{p}, x_{k}\right)=N\left(x_{p}, x_{k}\right)=\sigma_{b}\left(x_{p}, x_{k}\right)$. So

$$
\begin{aligned}
\frac{1}{2 s} & \sigma_{b}\left(x_{k}, x_{k+1}\right) \frac{1+\sigma_{b}\left(x_{p}, x_{p+1}\right)}{1+M\left(x_{p}, x_{k}\right)}+\frac{1}{2 s} N\left(x_{p}, x_{k}\right) \\
& \leq \frac{1}{2 s} \sigma_{b}\left(x_{k}, x_{k+1}\right)+\frac{1}{2 s} \sigma_{b}\left(x_{k}, x_{k+1}\right) \frac{\sigma_{b}\left(x_{p}, x_{p+1}\right)}{1+\sigma_{b}\left(x_{p}, x_{k}\right)}+\frac{1}{2 s} \sigma_{b}\left(x_{p}, x_{k}\right) \\
& <\frac{\delta^{\prime}}{8 s}+\frac{1}{2 s} \frac{\sigma_{b}\left(x_{k}, x_{k+1}\right)}{\sigma_{b}\left(x_{p}, x_{k}\right)} \sigma_{b}\left(x_{p}, x_{p+1}\right)+\frac{1}{2 s} \sigma_{b}\left(x_{p}, x_{k}\right) \\
& <\frac{\delta^{\prime}}{8 s}+\frac{1}{2 s} \sigma_{b}\left(x_{p}, x_{p+1}\right)+\frac{1}{2 s} \sigma_{b}\left(x_{p}, x_{k}\right) \\
& <\frac{\delta^{\prime}}{8 s}+\frac{\delta^{\prime}}{8 s}+\frac{1}{2 s} \sigma_{b}\left(x_{p}, x_{k}\right) \\
& <\frac{\delta^{\prime}}{4 s}+\frac{1}{2 s} s\left(2 \varepsilon+\frac{\delta^{\prime}}{2}\right) \\
& \leq \varepsilon+\frac{\delta^{\prime}}{2} .
\end{aligned}
$$

Therefore

$$
\frac{1}{2 s} \sigma_{b}\left(x_{k}, x_{k+1}\right) \frac{1+\sigma_{b}\left(x_{p}, x_{p+1}\right)}{1+M\left(x_{p}, x_{k}\right)}+\frac{1}{2 s} N\left(x_{p}, x_{k}\right)<\varepsilon+\frac{\delta^{\prime}}{2} .
$$

It follows from (15) and (16) that (14) holds. Then

$$
2 s \varepsilon \leq \sigma_{b}\left(x_{k}, T x_{k}\right) \frac{1+\sigma_{b}\left(x_{p}, T x_{p}\right)}{1+M\left(x_{p}, x_{k}\right)}+N\left(x_{p}, x_{k}\right)<s\left(2 \varepsilon+\delta^{\prime}\right),
$$


and from (9), (6) we conclude that

$$
\sigma_{b}\left(T x_{p}, T x_{k}\right) \leq \alpha\left(x_{p}, x_{k}\right) \sigma_{b}\left(T x_{p}, T x_{k}\right)<\varepsilon
$$

Now, using $\left(\sigma_{b} 3\right)$ together with (18) and (12) we obtain

$$
\sigma_{b}\left(T x_{p}, x_{k}\right) \leq s \sigma_{b}\left(T x_{p}, T x_{k}\right)+s \sigma_{b}\left(T x_{k}, x_{k}\right)<s\left(2 \varepsilon+\frac{\delta^{\prime}}{2}\right) .
$$

This implies that $T \lambda=T x_{p}=x_{p+1} \in \Lambda$.

Next, we suppose that $\sigma_{b}\left(x_{p}, x_{k}\right)<2 s \varepsilon$. From (7) we derive

$$
\begin{aligned}
\sigma_{b}\left(T x_{p}, x_{k}\right) \leq & s \sigma_{b}\left(T x_{p}, T x_{k}\right)+s \sigma_{b}\left(T x_{k}, x_{k}\right) \\
\leq & s \alpha\left(x_{p}, x_{k}\right) \sigma_{b}\left(T x_{p}, T x_{k}\right)+s \sigma_{b}\left(T x_{k}, x_{k}\right) \\
< & s\left[\frac{1}{2 s} \sigma_{b}\left(x_{k}, x_{k+1}\right) \frac{1+\sigma_{b}\left(x_{p}, x_{p+1}\right)}{1+M\left(x_{p}, x_{k}\right)}+\frac{1}{2 s} N\left(x_{p}, x_{k}\right)\right]+s \sigma_{b}\left(x_{k+1}, x_{k}\right) \\
\leq & \frac{1}{2} \sigma_{b}\left(x_{k}, x_{k+1}\right)+\frac{\sigma_{b}\left(x_{k}, x_{k+1}\right) \sigma_{b}\left(x_{p}, x_{p+1}\right)}{2\left(1+\sigma_{b}\left(x_{p}, x_{k}\right)\right)} \\
& +\frac{1}{2} N\left(x_{p}, x_{k}\right)+s \sigma_{b}\left(x_{k+1}, x_{k}\right) \\
\leq & \frac{\delta^{\prime}}{8}+\frac{\sigma_{b}\left(x_{k}, x_{k+1}\right) \sigma_{b}\left(x_{p}, x_{p+1}\right)}{2\left(1+\sigma_{b}\left(x_{p}, x_{k}\right)\right)}+\frac{1}{2} N\left(x_{p}, x_{k}\right)+s \frac{\delta^{\prime}}{4} .
\end{aligned}
$$

On the other hand, applying (12), we have

$$
\frac{\sigma_{b}\left(x_{k}, x_{k+1}\right)}{1+\sigma_{b}\left(x_{p}, x_{k}\right)} \leq \sigma_{b}\left(x_{k}, x_{k+1}\right)<\frac{\delta^{\prime}}{4}<1 .
$$

Then

$$
\begin{aligned}
\sigma_{b}\left(T x_{p}, x_{k}\right) & \leq \frac{\delta^{\prime}}{8}+\frac{1}{2} \sigma_{b}\left(x_{p}, x_{p+1}\right)+\frac{1}{2} N\left(x_{p}, x_{k}\right)+s \frac{\delta^{\prime}}{4} \\
& <\left[\frac{\delta^{\prime}}{8}+\frac{\delta^{\prime}}{8}+s \varepsilon\right]+s \frac{\delta^{\prime}}{4} \\
& \leq s\left(\frac{\delta^{\prime}}{2}+2 \varepsilon\right) .
\end{aligned}
$$

In turn this proves $T \lambda=T x_{p}=x_{p+1} \in \Lambda$. Hence $T(\Lambda) \subset \Lambda$ so

$$
\sigma_{b}\left(x_{m}, x_{k}\right)<s\left(\frac{\delta^{\prime}}{2}+2 \varepsilon\right), \quad \forall m>k \text {. }
$$

Now, for all $m, n \in \mathbb{N}$ such that $m>n>k$, by (19) we get

$$
\sigma_{b}\left(x_{m}, x_{n}\right) \leq s \sigma_{b}\left(x_{m}, x_{k}\right)+s \sigma_{b}\left(x_{k}, x_{n}\right)<s^{2}\left(4 \varepsilon+\delta^{\prime}\right) \leq 5 s^{2} \varepsilon .
$$

It follows that $\lim _{m, n \rightarrow \infty} \sigma_{b}\left(x_{m}, x_{n}\right)=0$. Hence $\left\{x_{n}\right\}$ is a Cauchy sequence in $X$ and since $X$ is complete there exists $z \in X$ such that

$$
\lim _{n, m \rightarrow \infty} \sigma_{b}\left(x_{n}, x_{m}\right)=\lim _{n \rightarrow \infty} \sigma_{b}\left(x_{n}, z\right)=\sigma_{b}(z, z)=0
$$


Finally, from (7) we observe that

$$
\begin{aligned}
\sigma_{b}(T z, z) & \leq s \sigma_{b}\left(T z, T x_{n}\right)+s \sigma_{b}\left(x_{n+1}, z\right) \\
& \leq s \alpha\left(z, x_{n}\right) \sigma_{b}\left(T z, T x_{n}\right)+s \sigma_{b}\left(x_{n+1}, z\right) \\
& <s\left[\frac{1}{2 s} \sigma_{b}\left(x_{n}, x_{n+1}\right) \frac{1+\sigma_{b}(z, T z)}{1+M\left(z, x_{n}\right)}+\frac{1}{2 s} N\left(z, x_{n}\right)\right]+s \sigma_{b}\left(x_{n+1}, z\right) .
\end{aligned}
$$

Applying the definition of $N\left(z, x_{n}\right)$, the right-hand side of the above inequality tends to $\frac{1}{4} \sigma_{b}(T z, z)$ when $n$ tends to infinity. It implies that $\sigma_{b}(T z, z)=0$ and $T z=z$.

The following example reveals the usefulness of Theorem 2.7.

Example 2.8 Let $X=\{0,1,2,3\}$. Define $\sigma_{b}: X \times X \rightarrow \mathbb{R}^{+}$as follows:

$$
\sigma_{b}(x, y)= \begin{cases}4, & x=y=0 \text { or } 2 \text { or } 3 \\ 0, & x=y=1 \\ 1, & x \neq y\end{cases}
$$

Clearly, $\left(X, \sigma_{b}\right)$ is a complete $b$-metric-like space with $s=2$. Consider $T: X \rightarrow X$ defined by $T 0=0, T 1=1, T 2=2$, and $T 3=1$. Also, define $\alpha: X \times X \rightarrow \mathbb{R}^{+}$as follows:

$$
\alpha(x, y)= \begin{cases}\frac{1}{5}, & x+y=1 \text { or } 3 \\ 0, & x=y=0 \\ 1, & x=y=1 \\ \frac{1}{x+y+1}, & \text { otherwise }\end{cases}
$$

It easily can be shown that $T$ is triangular $\alpha$-admissible. In order to check the condition (6), we choose $\delta=4 \varepsilon$ so that $4 \varepsilon \leq \sigma_{b}(y, T y) \frac{1+\sigma_{b}(x, T x)}{1+M(x, y)}+N(x, y)<8 \varepsilon$ which implies $\alpha(x, y) \sigma_{b}(T x, T y)<\varepsilon$.

Note that $\alpha(1, T 1) \geq 1, \alpha(T 1,1) \geq 1$. Now, all conditions of Theorem 2.7 are satisfied and so $T$ has a fixed point.

On the other hand, let $d_{\sigma_{b}}$ be the $b$-metric associated to $b$-metric-like $\sigma_{b}$ defined by $d_{\sigma_{b}}(x, y)=0$ if $x=y$ and $d_{\sigma_{b}}(x, y)=\sigma_{b}(x, y)$, elsewhere. Then condition (6) does not hold in $b$-metric space $\left(X, d_{\sigma_{b}}\right)$. Let $\varepsilon=\frac{1}{4}, x=0$, and $y=2$. Then $1=4 \varepsilon \leq d_{\sigma_{b}}(2, T 2) \frac{1+d_{\sigma_{b}}(0, T 0)}{1+M(0,2)}+$ $N(0,2)=1<4 \varepsilon+2 \delta=1+2 \delta$, for each $\delta>0$. But $\alpha(0,2) d_{\sigma_{b}}(T 0, T 2)=\frac{1}{3} \nless \frac{1}{4}$.

Theorem 2.9 Let $\left(X, \sigma_{b}\right)$ be a complete b-metric-like space and $T: X \rightarrow X$ be an $\alpha$ admissible mapping. Assume that there exists a function $\theta: \mathbb{R}^{+} \rightarrow \mathbb{R}^{+}$satisfying the following conditions:

(a) $\theta(0)=0$ and $\theta(t)>0$ for every $t>0$,

(b) $\theta$ is nondecreasing and right continuous,

(c) for every $\varepsilon>0$, there exists $\delta>0$ such that

$$
\begin{aligned}
& 2 \varepsilon \leq \theta\left(\frac{1}{s} \sigma_{b}(y, T y) \frac{1+\sigma_{b}(x, T x)}{1+M(x, y)}+\frac{1}{s} N(x, y)\right)<2 \varepsilon+\delta \quad \text { implies } \\
& \theta\left(2 \alpha(x, y) \sigma_{b}(T x, T y)\right)<2 \varepsilon
\end{aligned}
$$

for all $x, y \in X$, then (6) is satisfied. 
Proof Fix $\varepsilon>0$. Since $\theta(2 \varepsilon)>0$ by (c), there exists $\delta>0$ such that

$$
\begin{gathered}
\theta(2 \varepsilon) \leq \theta\left(\frac{1}{s} \sigma_{b}(y, T y) \frac{1+\sigma_{b}(x, T x)}{1+M(x, y)}+\frac{1}{s} N(x, y)\right)<\theta(2 \varepsilon)+\delta \\
\Rightarrow \quad \theta\left(2 \alpha(x, y) \sigma_{b}(T x, T y)\right)<\theta(2 \varepsilon) .
\end{gathered}
$$

In view of the fact that $\theta$ is right continuous, then there exists $\delta^{\prime}>0$ such that $\theta\left(2 \varepsilon+\delta^{\prime}\right)<$ $\theta(2 \varepsilon)+\delta$. Fix $x, y \in X$ such that

$$
2 \varepsilon \leq \frac{1}{s} \sigma_{b}(y, T y) \frac{1+\sigma_{b}(x, T x)}{1+M(x, y)}+\frac{1}{s} N(x, y)<2 \varepsilon+\delta^{\prime} .
$$

Since $\theta$ is nondecreasing we get

$$
\theta(2 \varepsilon) \leq \theta\left(\frac{1}{s} \sigma_{b}(y, T y) \frac{1+\sigma_{b}(x, T x)}{1+M(x, y)}+\frac{1}{s} N(x, y)\right)<\theta\left(2 \varepsilon+\delta^{\prime}\right)<\theta(2 \varepsilon)+\delta .
$$

In the light of (20), we conclude that

$$
\theta\left(2 \alpha(x, y) \sigma_{b}(T x, T y)\right)<\theta(2 \varepsilon)
$$

It enforces that $\alpha(x, y) \sigma_{b}(T x, T y)<\varepsilon$, i.e., (6) is satisfied.

Corollary 2.10 Let $\left(X, \sigma_{b}\right)$ be a complete $b$-metric-like space and $T: X \rightarrow X$ be a mapping. Let $\varphi$ be a locally integrable function from $\mathbb{R}^{+}$into itself such that $\int_{0}^{t} \varphi(s) d s>0$ for all $t>0$. Assume that conditions (a) and (b) of Theorem 2.7 hold and also $T$ fulfills the following condition for all $x, y \in X$ :

$$
\int_{0}^{2 \alpha(x, y) \sigma_{b}(T x, T y)} \varphi(t) d t \leq c \int_{0}^{\frac{1}{s} \sigma_{b}(y, T y) \frac{1+\sigma_{b}(x, T x)}{1+M(x, y)}+\frac{1}{s} N(x, y)} \varphi(t) d t
$$

where $c \in\left(0, \frac{1}{2 s}\right)$ is a constant. Then $T$ has a fixed point.

Proof As a result of Theorem 2.9 if for each $\varepsilon>0$, there exists $\delta>0$ such that

$$
2 \varepsilon \leq \int_{0}^{\frac{1}{s} \sigma_{b}(y, T y) \frac{1+\sigma_{b}(x, T x)}{1+M(x, y)}+\frac{1}{s} N(x, y)} \varphi(t) d t<2 \varepsilon+\delta \Rightarrow \int_{0}^{2 \alpha(x, y) \sigma_{b}(T x, T y)} \varphi(t) d t<2 \varepsilon,
$$

then (6) is satisfied.

Fix $\varepsilon>0$. Take $\delta=2 \varepsilon\left(\frac{1}{2 c}-1\right)$, then

$$
\int_{0}^{2 \alpha(x, y) \sigma_{b}(T x, T y)} \varphi(t) d t \leq c \int_{0}^{\frac{1}{s} \sigma_{b}(y, T y) \frac{1+\sigma_{b}(x, T x)}{1+M(x, y)}+\frac{1}{s} N(x, y)} \varphi(t) d t<c(2 \varepsilon+\delta)=\varepsilon<2 \varepsilon .
$$

Now, we establish an existence of fixed point of mapping satisfying generalized MeirKeeler contractions of type (I) in the setup of $b$-metric-like spaces. For this purpose, we need the following definition. 
Definition 2.11 Let $\left(X, \sigma_{b}\right)$ be a $b$-metric-like space, and let $T$ be a self-mapping on $X$. $T$ is called orbitally continuous whenever

$$
\lim _{n \rightarrow \infty} \sigma_{b}\left(T^{n} x, z\right)=\sigma_{b}(z, z) \Rightarrow \lim _{n \rightarrow \infty} \sigma_{b}\left(T T^{n} x, T z\right)=\sigma_{b}(T z, T z)
$$

for each $x, z \in X$.

It is clear that continuous mappings are orbitally continuous. But the converse may not be true. To show this, let $\left([0,1], \sigma_{b}\right)$ be the $b$-metric-like space, where $\sigma_{b}(x, y)=[\max \{x, y\}]^{q}$ $(q \geq 1)$. Consider $T: X \rightarrow X$ defined by

$$
T(x)= \begin{cases}\frac{x}{2}, & 0 \leq x<1, \\ 0, & x=1 .\end{cases}
$$

Clearly $T$ is not continuous but it is orbitally continuous.

Theorem 2.12 Let $\left(X, \sigma_{b}\right)$ be a complete b-metric-like space with coefficient $s$ and $T: X \rightarrow$ $X$ be a mapping. Suppose that the following conditions hold:

(a) $T$ is an orbitally continuous generalized Meir-Keeler contraction of type (I),

(b) there exists $x_{0} \in X$ such that $\alpha\left(x_{0}, T x_{0}\right) \geq 1, \alpha\left(T x_{0}, x_{0}\right) \geq 1$,

(c) if $\left\{x_{n}\right\}$ is a sequence in $X$ such that $x_{n} \rightarrow z$ as $n \rightarrow \infty$ and $\alpha\left(x_{n}, x_{m}\right) \geq 1$ for all $n, m \in \mathbb{N}$, then $\alpha(z, z) \geq 1$,

(d) $s>1$ or $\beta$ is a continuous function.

Then $T$ has a fixed point in $X$.

Proof Let $x_{0} \in X$ be such that condition (b) holds and define a sequence $\left\{x_{n}\right\}$ in $X$ so that $x_{1}=T x_{0}, x_{n+1}=T x_{n}$ for all $n \in \mathbb{N}$. Without loss of generality, we may suppose that $x_{n+1} \neq x_{n}$ for all $n \in \mathbb{N} \cup\{0\}$. Since $T$ is $\alpha$-admissible, then

$$
\alpha\left(x_{n}, x_{n+1}\right) \geq 1, \quad \forall n \in \mathbb{N} .
$$

Replace $x$ by $x_{n}$ and $y$ by $x_{n+1}$ in (2); we observe that for every $\varepsilon>0$ there exists $\delta>0$ such that

$$
\varepsilon \leq \beta\left(\sigma_{b}\left(x_{n}, x_{n+1}\right)\right) M\left(x_{n}, x_{n+1}\right)<\varepsilon+\delta \quad \Rightarrow \quad \alpha\left(x_{n}, x_{n+1}\right) \sigma_{b}\left(T x_{n}, T x_{n+1}\right)<\varepsilon
$$

where

$$
M\left(x_{n}, x_{n+1}\right)=\max \left\{\sigma_{b}\left(x_{n}, x_{n+1}\right), \sigma_{b}\left(x_{n+2}, x_{n+1}\right)\right\} .
$$

Next, we distinguish two following cases:

Case 1. Assume that $M\left(x_{n}, x_{n+1}\right)=\sigma_{b}\left(x_{n+2}, x_{n+1}\right)$. In this case equation (22) becomes

$$
\varepsilon \leq \beta\left(\sigma_{b}\left(x_{n}, x_{n+1}\right)\right) \sigma_{b}\left(x_{n+2}, x_{n+1}\right)<\varepsilon+\delta \quad \Rightarrow \quad \alpha\left(x_{n}, x_{n+1}\right) \sigma_{b}\left(T x_{n}, T x_{n+1}\right)<\varepsilon,
$$

and using (21) we have

$$
\begin{aligned}
\sigma_{b}\left(x_{n+1}, x_{n+2}\right) & \leq \alpha\left(x_{n}, x_{n+1}\right) \sigma_{b}\left(T x_{n}, T x_{n+1}\right)<\varepsilon \\
& \leq \beta\left(\sigma_{b}\left(x_{n}, x_{n+1}\right)\right) \sigma_{b}\left(x_{n+2}, x_{n+1}\right)<\sigma_{b}\left(x_{n+2}, x_{n+1}\right) .
\end{aligned}
$$


Hence, we deduce

$$
\sigma_{b}\left(x_{n+1}, x_{n+2}\right)<\sigma_{b}\left(x_{n+1}, x_{n+2}\right),
$$

for all $n \in \mathbb{N}$, which gives a contradiction.

Case 2. Assume that $M\left(x_{n}, x_{n+1}\right)=\sigma_{b}\left(x_{n}, x_{n+1}\right)$. Since $M\left(x_{n}, x_{n+1}\right)>0$, for all $n$, due to Remark 2.5, we get

$$
\begin{aligned}
\sigma_{b}\left(x_{n+1}, x_{n+2}\right) & \leq \alpha\left(x_{n}, x_{n+1}\right) \sigma_{b}\left(T x_{n}, T x_{n+1}\right) \\
& <\beta\left(\sigma_{b}\left(x_{n}, x_{n+1}\right)\right) \sigma_{b}\left(x_{n}, x_{n+1}\right) \\
& <\frac{1}{s} \sigma_{b}\left(x_{n}, x_{n+1}\right) \leq \sigma_{b}\left(x_{n}, x_{n+1}\right),
\end{aligned}
$$

for all $n$. That is, $\left\{\sigma_{b}\left(x_{n}, x_{n+1}\right)\right\}$ is a strictly decreasing positive sequence in $\mathbb{R}^{+}$and it converges to some $r \geq 0$. We declare that $r=0$. To support the claim, let it be untrue. Then we have $r>0$. We assert that

$$
0<r \leq \sigma_{b}\left(x_{n}, x_{n+1}\right), \quad \text { for all } n \in \mathbb{N} .
$$

First, suppose that $s>1$. Applying (23), we have

$$
\sigma_{b}\left(x_{n+1}, x_{n+2}\right)<\frac{1}{s} \sigma_{b}\left(x_{n}, x_{n+1}\right) .
$$

By taking the limit as $n$ tends to infinity we get $r \leq \frac{1}{s} r<r$, which is a contradiction and so $r=0$. Next, assume that $\beta$ is a continuous function. It is an easy verification that $\left\{\beta\left(\sigma_{b}\left(x_{n}, x_{n+1}\right)\right) \sigma_{b}\left(x_{n}, x_{n+1}\right)\right\}$ is a strictly decreasing positive sequence in $\mathbb{R}^{+}$and it converges to some $r^{\prime} \geq 0$. We consider the two following cases:

(I) $r^{\prime}=0$.

Since $\lim _{n \rightarrow \infty} \sigma_{b}\left(x_{n}, x_{n+1}\right) \neq 0$, so we have

$$
\exists \varepsilon>0, \forall k \in \mathbb{N}, \exists n_{k} \geq k ; \quad \sigma_{b}\left(x_{n_{k}}, x_{n_{k}+1}\right) \geq \varepsilon .
$$

Now, let $\varepsilon^{\prime}>0$ be given. Since $\lim _{k \rightarrow \infty} \beta\left(\sigma_{b}\left(x_{n_{k}}, x_{n_{k}+1}\right)\right) \sigma_{b}\left(x_{n_{k}}, x_{n_{k}+1}\right)=0$, therefore using (25) we derive

$$
\exists k^{\prime} \in \mathbb{N}, \forall k \geq k^{\prime} ; \quad \varepsilon \beta\left(\sigma_{b}\left(x_{n_{k}}, x_{n_{k}+1}\right)\right) \leq \beta\left(\sigma_{b}\left(x_{n_{k}}, x_{n_{k}+1}\right)\right) \sigma_{b}\left(x_{n_{k}}, x_{n_{k}+1}\right)<\varepsilon^{\prime} .
$$

It enforces that $\lim _{k \rightarrow \infty} \beta\left(\sigma_{b}\left(x_{n_{k}}, x_{n_{k}+1}\right)\right)=0$. Now, continuity of $\beta$ implies that $\beta(r)=0$, which is a contradiction.

(II) $r^{\prime}>0$.

If $r<r^{\prime}$, then $\beta\left(\sigma_{b}\left(x_{n}, x_{n+1}\right)\right) \sigma_{b}\left(x_{n}, x_{n+1}\right)<\frac{1}{s} \sigma_{b}\left(x_{n}, x_{n+1}\right)$, and by taking the limit as $n$ tends to infinity we get $r^{\prime} \leq \frac{r}{s} \leq r$, which is in contradiction with our assumption. Now, we suppose that $r \geq r^{\prime}$. Let $\delta>0$ be such that satisfying (2) whenever $\varepsilon=r^{\prime}$. We know that there exists $N_{0} \in \mathbb{N}$ such that

$$
r^{\prime} \leq \beta\left(\sigma_{b}\left(x_{N_{0}}, x_{N_{0}+1}\right)\right) \sigma_{b}\left(x_{N_{0}}, x_{N_{0}+1}\right)<r^{\prime}+\delta .
$$


Thus, $\sigma_{b}\left(x_{N_{0}+1}, x_{N_{0}+2}\right) \leq \alpha\left(x_{N_{0}}, x_{N_{0}+1}\right) \sigma_{b}\left(T x_{N_{0}}, T x_{N_{0}+1}\right)<r^{\prime} \leq r$, which leads to a contradiction with the condition (24). Thus, $r=0$ and so

$$
\lim _{n \rightarrow \infty} \sigma_{b}\left(x_{n}, x_{n+1}\right)=0 .
$$

Next, we intend to show that the sequence $\left\{x_{n}\right\}$ is a Cauchy sequence in $\left(X, \sigma_{b}\right)$. For this purpose, we will prove that for every $\varepsilon>0$ there exists $N \in \mathbb{N}$ such that

$$
\sigma_{b}\left(x_{l}, x_{l+k}\right)<\varepsilon
$$

for all $l \geq N$ and $k \in \mathbb{N}$. Since the sequence $\left\{\sigma_{b}\left(x_{n}, x_{n+1}\right)\right\}$ converges to 0 as $n \rightarrow \infty$, for every $\delta>0$ there exists $N \in \mathbb{N}$ such that

$$
\sigma_{b}\left(x_{n}, x_{n+1}\right)<\delta, \quad \text { for all } n \geq N \text {. }
$$

Choose $\delta$ such that $\delta<\varepsilon$. We will prove (26) by using induction on $k$. For $k=1$, (26) becomes

$$
\sigma_{b}\left(x_{l}, x_{l+1}\right)<\varepsilon
$$

and it clearly holds for all $l \geq N$ (due to the choice of $\delta$ ). Assume that the inequality (26) holds for some $k=m$, that is,

$$
\sigma_{b}\left(x_{l}, x_{l+m}\right)<\varepsilon, \quad \text { for all } l \geq N \text {. }
$$

For $k=m+1$ we have to show that $\sigma_{b}\left(x_{l}, x_{l+m+1}\right)<\varepsilon$ for all $l \geq N$. Employing the condition $\left(\sigma_{b} 3\right)$, we get

$$
\sigma_{b}\left(x_{l-1}, x_{l+m}\right) \leq s\left[\sigma_{b}\left(x_{l-1}, x_{l}\right)+\sigma_{b}\left(x_{l}, x_{l+m}\right)\right]<s(\delta+\varepsilon),
$$

for all $l \geq N$. If $\beta\left(\sigma_{b}\left(x_{l-1}, x_{l+m}\right)\right) \sigma_{b}\left(x_{l-1}, x_{l+m}\right) \geq \varepsilon$, then we deduce

$$
\begin{aligned}
\varepsilon & \leq \beta\left(\sigma_{b}\left(x_{l-1}, x_{l+m}\right)\right) \sigma_{b}\left(x_{l-1}, x_{l+m}\right) \\
& \leq \beta\left(\sigma_{b}\left(x_{l-1}, x_{l+m}\right)\right) M\left(x_{l-1}, x_{l+m}\right) \\
& =\beta\left(\sigma_{b}\left(x_{l-1}, x_{l+m}\right)\right) \max \left\{\sigma_{b}\left(x_{l-1}, x_{l+m}\right), \sigma_{b}\left(x_{l}, x_{l-1}\right), \sigma_{b}\left(x_{l+m+1}, x_{l+m}\right)\right\} \\
& <\beta\left(\sigma_{b}\left(x_{l-1}, x_{l+m}\right)\right) \max \{s(\varepsilon+\delta), \delta, \delta\} \\
& <\varepsilon+\delta,
\end{aligned}
$$

and according to Lemma 1.14, on using the contractive condition (2) with $x=x_{l-1}, y=x_{l+m}$ we find

$$
\varepsilon \leq \beta\left(\sigma_{b}\left(x_{l-1}, x_{l+m}\right)\right) M\left(x_{l-1}, x_{l+m}\right)<\delta+\varepsilon,
$$

which in turn implies that

$$
\sigma_{b}\left(x_{l}, x_{l+m+1}\right) \leq \alpha\left(x_{l-1}, x_{l+m}\right) \sigma_{b}\left(x_{l}, x_{l+m+1}\right)=\alpha\left(x_{l-1}, x_{l+m}\right) \sigma_{b}\left(T x_{l-1}, T x_{l+m}\right)<\varepsilon,
$$


and hence (26) holds for $k=m+1$. If $\beta\left(\sigma_{b}\left(x_{l-1}, x_{l+m}\right)\right) \sigma_{b}\left(x_{l-1}, x_{l+m}\right)<\varepsilon$, then

$$
\begin{aligned}
& \beta\left(\sigma_{b}\left(x_{l-1}, x_{l+m}\right)\right) M\left(x_{l-1}, x_{l+m}\right) \\
& \quad=\beta\left(\sigma_{b}\left(x_{l-1}, x_{l+m}\right)\right) \max \left\{\sigma_{b}\left(x_{l-1}, x_{l+m}\right), \sigma_{b}\left(x_{l}, x_{l-1}\right), \sigma_{b}\left(x_{l+m+1}, x_{l+m}\right)\right\} \\
& \quad<\beta\left(\sigma_{b}\left(x_{l-1}, x_{l+m}\right)\right) \max \left\{\sigma_{b}\left(x_{l-1}, x_{l+m}\right), \delta, \delta\right\}<\varepsilon .
\end{aligned}
$$

Regarding Remark 2.5, we get

$$
\sigma_{b}\left(x_{l}, x_{l+m+1}\right) \leq \alpha\left(x_{l-1}, x_{l+m}\right) \sigma_{b}\left(T x_{l-1}, T x_{l+m}\right)<\beta\left(\sigma_{b}\left(x_{l-1}, x_{l+m}\right)\right) M\left(x_{l-1}, x_{l+m}\right)<\varepsilon,
$$

that is, (26) holds for $k=m+1$. Note that $M\left(x_{l-1}, x_{l+m}\right)>0$, otherwise $\sigma_{b}\left(x_{l}, x_{l-1}\right)=0$, and hence $x_{l}=x_{l-1}$, which is in contradiction with our assumption. Thus $\sigma_{b}\left(x_{l}, x_{l+k}\right)<\varepsilon$ for all $l \geq N$ and $k \geq 1$, it means

$$
\sigma_{b}\left(x_{n}, x_{m}\right)<\varepsilon, \quad \text { for all } m \geq n \geq N .
$$

Therefore $\lim _{n, m \rightarrow \infty} \sigma_{b}\left(x_{n}, x_{m}\right)=0$ and since $X$ is a complete $b$-metric-like space, there exists $z \in X$ such that

$$
\lim _{n, m \rightarrow \infty} \sigma_{b}\left(x_{n}, x_{m}\right)=\lim _{n \rightarrow \infty} \sigma_{b}\left(x_{n}, z\right)=\sigma_{b}(z, z)=0 .
$$

Next, we will show that $z$ is a fixed point of $T$. We aim to show that $\sigma_{b}(T z, z)=0$. Assume that $\sigma_{b}(T z, z)>0$. Thus we have $M(z, z) \geq \sigma_{b}(T z, z)>0$ and applying orbitally continuity of $T$ it follows that

$$
\lim _{n \rightarrow \infty} \sigma_{b}\left(T T^{n} x_{0}, T z\right)=\lim _{n \rightarrow \infty} \sigma_{b}\left(x_{n+1}, T z\right)=\sigma_{b}(T z, T z) .
$$

So $\left\{x_{n+1}\right\}$ converges to $T z$. Using $\left(\sigma_{b} 3\right)$, we have

$$
\begin{aligned}
\sigma_{b}(T z, z) & \leq s \sigma_{b}\left(T z, x_{n+1}\right)+s \sigma_{b}\left(x_{n+1}, z\right) \\
& \leq s \sigma_{b}(T z, T z) \quad(\text { as } n \rightarrow \infty) .
\end{aligned}
$$

Therefore we deduce

$$
\begin{aligned}
\sigma_{b}(T z, T z) & \leq \alpha(z, z) \sigma_{b}(T z, T z) \\
& <\beta\left(\sigma_{b}(z, z)\right) M(z, z) \\
& <\frac{1}{s} \max \left\{\sigma_{b}(z, z), \sigma_{b}(T z, z)\right\} \\
& =\frac{1}{s} \sigma_{b}(T z, z) \\
& \leq \sigma_{b}(T z, T z),
\end{aligned}
$$

which is a contradiction. Consequently, $T z=z$.

By Remark 2.6 we know $N(x, y) \leq M(x, y)$, so a slight change in the proof of Theorem 2.12 shows actually the following theorem holds. 
Theorem 2.13 Let $\left(X, \sigma_{b}\right)$ be a complete $b$-metric-like space, $T: X \rightarrow X$ be a mapping. Suppose that the following conditions hold:

(a) $T$ is an orbitally continuous generalized Meir-Keeler contraction of type (II),

(b) there exists $x_{0} \in X$ such that $\alpha\left(x_{0}, T x_{0}\right) \geq 1, \alpha\left(T x_{0}, x_{0}\right) \geq 1$,

(c) if $\left\{x_{n}\right\}$ is a sequence in $X$ such that $x_{n} \rightarrow z$ as $n \rightarrow \infty$ and $\alpha\left(x_{n}, x_{m}\right) \geq 1$ for all $n, m \in \mathbb{N}$, then $\alpha(z, z) \geq 1$,

(d) $s>1$ or $\beta$ is a continuous function.

Then $T$ has a fixed point in $X$.

There is an analogous result for the generalized Meir-Keeler contraction. The proof is an easy adaptation of the one given in Theorem 2.12.

Proposition 2.14 Under the hypotheses of Theorem 2.12 consider a particular case, $T$ is a generalized Meir-Keeler contraction, then $T$ has a fixed point in X.

It is useful to seek a suitable replacement for the orbitally continuity of the contraction $T$. The next theorem indicates how this can be achieved. In fact with the aid of $\alpha$-admissibility of the contraction we will show that orbitally continuity assumption is not required whenever the following condition is satisfied.

(A) If $\left\{x_{n}\right\}$ is a sequence in $X$ which converges to $z$ with respect to $\tau_{\sigma_{b}}$ and satisfies $\alpha\left(x_{n+1}, x_{n}\right) \geq 1$ and $\alpha\left(x_{n}, x_{n+1}\right) \geq 1$ for all $n$, then there exists a subsequence $\left\{x_{n_{k}}\right\}$ of $\left\{x_{n}\right\}$ such that $\alpha\left(z, x_{n_{k}}\right) \geq 1$ and $\alpha\left(x_{n_{k}}, z\right) \geq 1$ for all $k$.

Theorem 2.15 Let $\left(X, \sigma_{b}\right)$ be a complete b-metric-like space with coefficient s and satisfies the condition (A). Also, let $T: X \rightarrow X$ be a mapping. Suppose that the following conditions hold:

(a) $T: X \rightarrow X$ is a generalized Meir-Keeler contraction of type (II),

(b) there exists $x_{0} \in X$ such that $\alpha\left(x_{0}, T x_{0}\right) \geq 1, \alpha\left(T x_{0}, x_{0}\right) \geq 1$,

(c) $s>1$ or $\beta$ is a continuous function.

Then $T$ has a fixed point in $X$.

Proof Following the proof of Theorem 2.7, we observe that the sequence $\left\{x_{n}\right\}$ defined by $x_{1}=T x_{0}$ and $x_{n+1}=T x_{n}(n \in \mathbb{N})$, converges to some $z \in X$ with $\sigma_{b}(z, z)=0$. By condition (A), there exists a subsequence $\left\{x_{n_{k}}\right\}$ of $\left\{x_{n}\right\}$ such that $\alpha\left(z, x_{n_{k}}\right) \geq 1$ and $\alpha\left(x_{n_{k}}, z\right) \geq 1$ for all $k$. Note that if $N\left(z, x_{n_{k}}\right)=0$, then $T z=z$ and the proof is done. Regarding Remark 2.5, for all $k \in \mathbb{N}$ we have

$$
\sigma_{b}\left(T z, x_{n_{k+1}}\right)=\sigma_{b}\left(T z, T x_{n_{k}}\right) \leq \alpha\left(z, x_{n_{k}}\right) \sigma_{b}\left(T z, T x_{n_{k}}\right)<\beta\left(\sigma_{b}\left(z, x_{n_{k}}\right)\right) N\left(z, x_{n_{k}}\right),
$$

where

$$
N\left(z, x_{n_{k}}\right)=\max \left\{\sigma_{b}\left(z, x_{n_{k}}\right), \frac{1}{2}\left[\sigma_{b}(T z, z)+\sigma_{b}\left(T x_{n_{k}}, x_{n_{k}}\right)\right]\right\} .
$$

Now on taking the limit $k \rightarrow \infty$ and applying $\left(\sigma_{b} 3\right)$ we obtain

$$
\lim _{k \rightarrow \infty} N\left(z, x_{n_{k}}\right)=\max \left\{0, \frac{1}{2} \sigma_{b}(T z, z)\right\}=\frac{1}{2} \sigma_{b}(T z, z) .
$$


Thus, we conclude that

$$
\lim _{k \rightarrow \infty} \sigma_{b}\left(T z, x_{n_{k+1}}\right) \leq \frac{1}{2 s} \sigma_{b}(T z, z) .
$$

Applying again $\left(\sigma_{b} 3\right)$, we have

$$
\sigma_{b}(T z, z) \leq s \sigma_{b}\left(T z, x_{n_{k+1}}\right)+s \sigma_{b}\left(x_{n_{k+1}}, z\right)
$$

and passing to the limit $k \rightarrow \infty$ in the above relation we obtain

$$
\sigma_{b}(T z, z) \leq \frac{1}{2} \sigma_{b}(T z, z)
$$

This inequality implies $\sigma_{b}(T z, z)=0$ and hence $T z=z$, which completes the proof.

Proposition 2.16 Let $\left(X, \sigma_{b}\right)$ be a complete $b$-metric-like space with coefficient $s$ and satisfies the condition (A). Let $T: X \rightarrow X$ be a generalized Meir-Keeler contraction. Also, suppose that the following conditions hold:

(a) there exists $x_{0} \in X$ such that $\alpha\left(x_{0}, T x_{0}\right) \geq 1, \alpha\left(T x_{0}, x_{0}\right) \geq 1$,

(b) $s>1$ or $\beta$ is a continuous function.

Then $T$ has a fixed point in $X$.

The usability of these results is demonstrated by the two following examples.

Example 2.17 Let $\left(X, \sigma_{b}\right)$ and $\alpha$ be as in Example 2.8. Consider $T: X \rightarrow X$ defined by $T 0=T 2=0$ and $T 1=2$. Also, define $\beta:[0,+\infty) \rightarrow\left(0, \frac{1}{s}\right)$ as follows:

$$
\beta(x)= \begin{cases}\frac{1}{x}, & x=3,4,8, \\ \frac{5}{9(x+1)}, & \text { otherwise. }\end{cases}
$$

In order to check the condition (2), we choose $\delta=\varepsilon$ so that $\varepsilon \leq \beta\left(\sigma_{b}(x, y)\right) M(x, y)<\varepsilon+\delta=$ $2 \varepsilon$, which implies $\alpha(x, y) \sigma_{b}(T x, T y)<\varepsilon$.

Therefore, the map $T$ is a generalized Meir-Keeler contraction of type (I). Note that $T$ is continuous with respect to $\tau_{\sigma_{b}}$ and $\alpha(0, T 0) \geq 1, \alpha(T 0,0) \geq 1$. Now, all conditions of Theorem 2.12 are satisfied and so $T$ has a fixed point.

Example 2.18 Let $X=\mathbb{R}^{+}$equipped with the $b$-metric-like $\sigma_{b}: X \times X \rightarrow \mathbb{R}^{+}$defined by

$$
\sigma_{b}(x, y)=\left(x^{2}+y^{2}\right)^{2}
$$

It is easy to see that $\left(X, \sigma_{b}\right)$ is a complete $b$-metric-like space, with $s=2$. Define the selfmapping $T: X \rightarrow X$ and the functions $\alpha: X \times X \rightarrow[0,+\infty), \beta:[0,+\infty) \rightarrow\left(0, \frac{1}{s}\right)$ as follows:

$$
\begin{gathered}
T(x)= \begin{cases}\frac{x}{2}, & x \in[0,1], \\
\log \left(2 x^{5}+x^{4}+4 x^{2}+4\right), & x \in(1,+\infty),\end{cases} \\
\alpha(x, y)=\left\{\begin{array}{lll}
1, & x, y \in[0,1], \\
0, & \text { otherwise, }
\end{array} \quad \beta(x)= \begin{cases}\frac{1}{4}, & x \in[0,1], \\
\frac{x}{3 x+1}, & \text { otherwise. }\end{cases} \right.
\end{gathered}
$$


Then the mapping $T$ is triangular $\alpha$-admissible. On the other hand, the condition (A) holds on $X$. More precisely, if the sequence $\left\{x_{n}\right\} \subset X$ satisfies $\alpha\left(x_{n}, x_{n+1}\right) \geq 1, \alpha\left(x_{n+1}, x_{n}\right) \geq 1$, and $\lim _{n \rightarrow \infty} x_{n}=x$ with respect to $\tau_{\sigma_{b}}$, for some $x \in X$, then $\left\{x_{n}\right\} \subset[0,1]$ and, moreover, $\lim _{n \rightarrow \infty}\left(x_{n}^{2}+x^{2}\right)^{2}=4 x^{4}$, which gives us $x=0$. Hence $\alpha\left(x_{n}, x\right) \geq 1$ and $\alpha\left(x, x_{n}\right) \geq 1$.

Next we prove that $T$ is a generalized Meir-Keeler contraction. We show this in the three following steps.

Step 1 . If $x \notin[0,1]$ or $y \notin[0,1]$.

In this case, $\alpha(x, y)=0$ and evidently (1) holds.

Step 2. Let $x, y \in[0,1]$ with $\sigma_{b}(x, y) \in[0,1]$.

Let $\varepsilon>0$ be given and choose $\delta=3 \varepsilon$. Now if $\varepsilon \leq \beta\left(\sigma_{b}(x, y)\right) \sigma_{b}(x, y)=\frac{1}{4}\left(x^{2}+y^{2}\right)^{2}<\varepsilon+\delta=$ $4 \varepsilon$, then

$$
\alpha(x, y) \sigma_{b}(T x, T y)=\left(\frac{x^{2}}{4}+\frac{y^{2}}{4}\right)^{2}=\frac{1}{16}\left(x^{2}+y^{2}\right)^{2}<\varepsilon .
$$

Step 3. Let $x, y \in[0,1]$ with $\sigma_{b}(x, y) \notin[0,1]$.

Take $\delta=3 \varepsilon$. Then the inequality $\varepsilon \leq \beta\left(\sigma_{b}(x, y)\right) \sigma_{b}(x, y)=\frac{\left(x^{2}+y^{2}\right)^{4}}{3\left(x^{2}+y^{2}\right)^{2}+1}<4 \varepsilon$, implies that $\alpha(x, y) \sigma_{b}(T x, T y)=\frac{1}{16}\left(x^{2}+y^{2}\right)^{2}<\varepsilon$.

Also, notice that $\alpha(0, T 0) \geq 1$ and $\alpha(T 0,0) \geq 1$. We conclude that all of the assumptions of Proposition 2.16 are satisfied. Moreover, $T$ has fixed points $x=0$ and $x=2$.

A remarkable fact concerning Example 2.18 is that the restriction of $T$ to the interval $[0,1]$ is orbitally continuous and so by the definition of $\alpha$ that example fulfills all conditions of Theorem 2.12, too.

\section{Competing interests}

The authors declare that they have no competing interests.

\section{Authors' contributions}

All authors contributed equally to the writing of this paper. All authors read and approved the final manuscript.

\section{Acknowledgements}

The authors gratefully acknowledge the anonymous reviewers for their carefully reading of the paper and helpful suggestions.

Received: 17 November 2015 Accepted: 27 February 2016 Published online: 15 March 2016

\section{References}

1. Meir, A, Keeler, E: A theorem on contraction mappings. J. Math. Anal. Appl. 28, 326-329 (1969)

2. Banach, S: Sur les opérations dans les ensembles abstraits et leur application aux équations intégrales. Fundam. Math. 3, 133-181 (1922)

3. Alsulami, HH, Gülyaz, S, Erhan, iM: Fixed points of $\alpha$-admissible Meir-Keeler contraction mappings on quasi-metric spaces. J. Inequal. Appl. 2015, Article ID 84 (2015)

4. Samet, B, Vetro, C, Vetro, P: Fixed point theorems for $\alpha-\psi$ contractive type mappings. Nonlinear Anal. 75, 2154-2165 (2012)

5. Aydi, H, Karapinar, E, Rezapour, S: A generalized Meir-Keeler contraction on partial metric spaces. Abstr. Appl. Anal. 2012, Article ID 287127 (2012)

6. Erduran, A, Imdad, M: Coupled fixed point theorems for generalized Meir-Keeler contractions in ordered partial metric spaces. Nonlinear Anal. Appl. 2012, Article ID jnaa-00169 (2012)

7. Karapinar, E, Kumam, P, Salimi, P: On $(\alpha-\psi)$-Meir-Keeler contractive mappings. Fixed Point Theory Appl. 2013, Article ID 94 (2013)

8. Samet, B, Vetro, C, Yazidi, H: A fixed point theorem for a Meir-Keeler type contraction through rational expression. J. Nonlinear Sci. Appl. 6, 162-169 (2013)

9. Amini-Harandi, A: Metric-like spaces, partial metric spaces and fixed points. Fixed Point Theory Appl. 2012, Article ID 204 (2012)

10. Matthews, SG: Partial metric topology. In: Proc. 8th Summer Conference on General Topology and Applications. Ann. New York Acad. Sci., vol. 728, pp. 183-197 (1994)

11. Czerwik, S: Contraction mappings in b-metric spaces. Acta Math. Inform. Univ. Ostrav. 1, 5-11 (1993) 
12. Alghamdi, MA, Hussain, N, Salimi, P: Fixed point and coupled fixed point theorems on b-metric-like spaces. J. Inequal. Appl. 2013, Article ID 402 (2013)

13. Khamsi, MA: Generalized metric spaces: a survey. J. Fixed Point Theory Appl. 17(3), 455-475 (2015)

14. Kirk, W, Shahzad, N: Fixed Point Theory in Distance Spaces. Springer, Cham (2014). ISBN:978-3-319-10927-5

15. An, TV, Dung, NV, Kadelburg, Z, Radenović, S: Various generalizations of metric spaces and fixed point theorems. Rev. R. Acad. Cienc. Exactas Fís. Nat., Ser. A Mat. 109, 175-198 (2015)

16. Shukla, S: Partial $b$-metric spaces and fixed points theorems. Mediterr. J. Math. 11, 703-711 (2014)

17. Shobkolaei, N, Sedghi, S, Roshan, JR, Hussain, N: Suzukitype fixed point results in metric-like spaces. J. Funct. Spaces Appl. 2013, Article ID 143686 (2013)

18. Hussain, N, Roshan, JR, Parvaneh, V, Kadelburg, Z: Fixed point of contractive mapping in b-metric-like spaces. Sci. World J. 2014, Article ID 471827 (2014)

19. Chan, C, Dong, J, Zhu, C: Some fixed point theorems in b-metric-like spaces. Fixed Point Theory Appl. 2015, Article ID 122 (2015)

20. Karapinar, E, Samet, B: Generalized $(\alpha-\psi)$ contractive type mapping and related fixed point theorems with applications. Abstr. Appl. Anal. 2012, Article ID 793486 (2012)

Submit your manuscript to a SpringerOpen ${ }^{\circ}$ journal and benefit from:

- Convenient online submission

Rigorous peer review

- Immediate publication on acceptance

- Open access: articles freely available online

- High visibility within the field

- Retaining the copyright to your article 